\title{
Biomedical Applications of Single Protein Nanoparticles
}

\author{
Imre Hegedüs ${ }^{1}$, Mihály Kálmán ${ }^{2}$, Eszter Faragó ${ }^{3}$ and Endre Nagy ${ }^{1}$ \\ 1. Research Institute of Chemical and Process Engineering, University of Pannonia, Veszprém H-8200, Hungary \\ 2. Department of Anatomy, Histology and Embryology, Semmelweis University, Budapest H-1450, Hungary \\ 3. Institute of Physical Chemistry, Eotvos Lorand University, Budapest H-1518, Hungary
}

\begin{abstract}
The drug carrier function of single protein nanoparticles, i.e., each individual protein molecule covered by a very thin, porous and few nanometer thick polymer layer, has been investigated. This layer around protein molecule is very thin, about 3-5 nm thick and highly porous, thus it does not reduce seriously the enzymatic function of protein molecule. The spatial structure of encapsulated protein molecule, which is essential in its function, can be stabilized by this polymer layer. Bovine serum albumin was used as protein drug molecule and it was encapsulated with acrylamide-bisarylamide random copolymer. The polymerization, starting from the modified sites of the surface of bovine serum albumin molecules was initiated by TEMED (tetramethylethylenediamine). These single albumin nanoparticles were painted with fluorescein isothiocyanate. This material was then injected into the inferior vena cava of rats. The treated rats were decapitated after 1 to 10 minutes and its brain was investigated by fluorescent microscopy. It was proved that bovine serum albumin molecules as drugs encapsulated in polymer nano-layer with a reduced size (about $10 \mathrm{~nm}$ ) can pass through the blood brain barrier. The results suggest that this method is capable of transformation of biomacromolecules to access the brain tissue via the blood.
\end{abstract}

Key words: Single protein nanoparticles, bovine serum albumin, drug carrier, blood-brain barrier.

\section{Nomenclature}

$\begin{array}{ll}\text { BSA } & \text { Bovine serum albumin } \\ \text { FITC } & \text { Fluorescein isothiocyanate } \\ \text { FITC-BSA } & \text { BSA conjugated with FITC } \\ \text { FITC-SPN-BSA } & \text { SPN from FITC-BSA } \\ \text { SPN } & \text { Single protein nanoparticles } \\ \text { TEMED } & \text { N,N,N',N'-tetramethylethylenediamine }\end{array}$

\section{Introduction ${ }^{1}$}

Proteins as drugs are widely applied therapeutic agents [1]. Proteins are very sensitive to a little change of their microenvironment $(\mathrm{pH}$, ionic strange, temperature, etc.) [1]. Otherwise proteins have a limited biological lifetime in the systemic circulation because protease enzymes can break them down easily before protein drugs can perform its therapeutic function [2]. Proteins usually have enzymatic activity. The most effectively studied areas of enzymatic reactions are pharmaceutics [3]. Increase of the

Corresponding author: Imre Hegedus, M.Sc., research fields: nanobiotechnology, enzyme and protein stabilization. E-mail address: hegedus@ mukki.richem.hu. catalytic lifetime and stability of enzymes are crucial to widen usage of enzymes. Improvement in enzyme stability can reduce the amount of enzyme required, can extend the lifetime of enzymes and can increase the reuse of enzymes.

Protein modification is a covalent reaction between the functional groups on the surface of enzyme molecule and chemicals, e.g., polymers in order to change the chemical feature of enzyme surface, which can lead to greater stability of the pretreated enzyme [4-9]. Protein stabilization techniques, such as protein engineering [10-13], reaction medium engineering [7, $14,15]$ and protein immobilization are often applied methods in order to stabilize enzyme catalytic activity, i.e., to increase its functional time [6], though immobilized enzymes often have lesser activity than the native ones [16, 17]. Protein or enzyme immobilization means an attachment of protein to the surface or onto the inner cavities of greater structures with adsorption or covalent linkage [4,5]. Covalent linkage between the protein molecule and carrier 
material can reduce the unfolding mechanism of ternary structure of protein molecule.

Nowadays, researchers realize that the size reduction of carrier materials can increase the catalytic efficiency of enzymes. Enzyme carriers with a small size have greater active surface and to this greater surface can attach more enzymes, and it can lead to much higher amount of enzyme per unit mass. On the other hand, nanoparticles as drugs with reduced size tend to accumulate in tumors, with less side effect on other parts of the organism [18].

There are two main modes to stabilize enzymes: (1) "grafting onto" techniques which mean a two-step preparation: the nanoparticles are prepared at first and after it the enzyme conjugation comes as a second, separated process $[19,20]$. (2) in the case of "grafting from" techniques, the stabilizing layer is synthesized directly from the surface of the enzyme molecules [21-27]. These methods are illustrated on Fig. 1.

Single protein nanoparticles which is applied here as nano-carrier, means that every individual protein molecule is covered with a very thin, few nanometers thick polymer layer. Stability features of single enzyme nanoparticles have been studied in the literature using organic/inorganic hybrid layer [28-32] and organic acrylic copolymer [33]. The nano-layer around the enzymes has different functions, e.g., different types of stability increase (Fig. 2), drug carrier function, intracellular delivery agent, immune isolation function. The stabilization function can be divided as: (1) mechanical stability, when under mechanical stress (circular stirring at $150 \mathrm{rpm}$ ) the single enzyme nanoparticles seem to be more stable than control natural enzymes (enzymes without nano-layer) [29, 30, 32]. (2) Heat stability, when single enzyme nanoparticles have greater stability than natural enzymes at extremely high temperature $\left(80{ }^{\circ} \mathrm{C}\right)$ [32]; (3) pH-stability, when the activity of single enzyme nanoparticles does not reduce under extremely acidic $(\mathrm{pH}=1.5)$ or basic $(\mathrm{pH}=12.0) \mathrm{pH}$-values, while the natural enzymes almost loose its activity [29, 32]. It can be assumed that the polymer nano-layer around the SPNs not only has stabilization function, but also has drug carrier function in living organisms. Recently, single protein nanoparticles were demonstrated as intracellular delivery platforms. The nano-layer protects the therapeutic protein against the degradation by proteases in the systemic circulation [34]. Furthermore, responsive polymer layers can releases its protein cargoes in the cell under specific local intracellular conditions or events, e.g., (1) at low $\mathrm{pH}$ values in endosomes ( $\mathrm{pH} 5.5)$ [34] or (2) enzyme digestion [35].

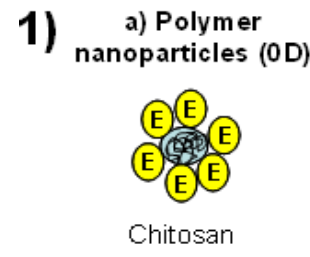

c) Monomolecular films (2D)

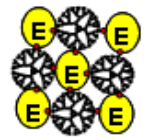

G4 PAMAM dendrimer b) Polym er fibers

(1D)

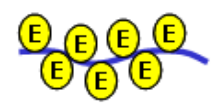

d) Spatial polymer network (3D)

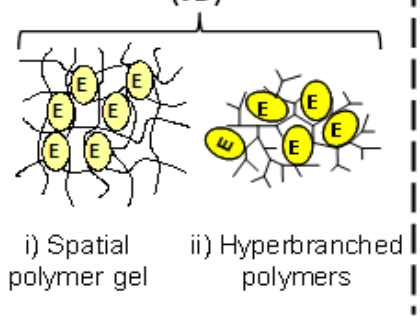

2)

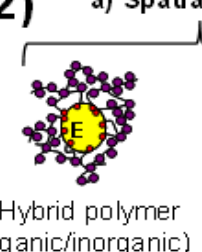

(organic/inorganic)

c) Hiperbranched polymer

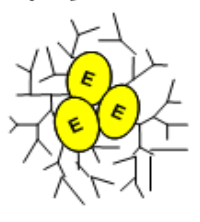

b) dendron
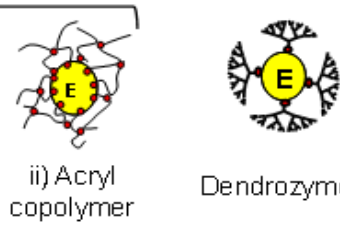

Dendrozymes

(E) = enzyme molecule

- = covalent linkage

Fig. 1 Enzyme stabilization techniques using nano-sized carriers. 


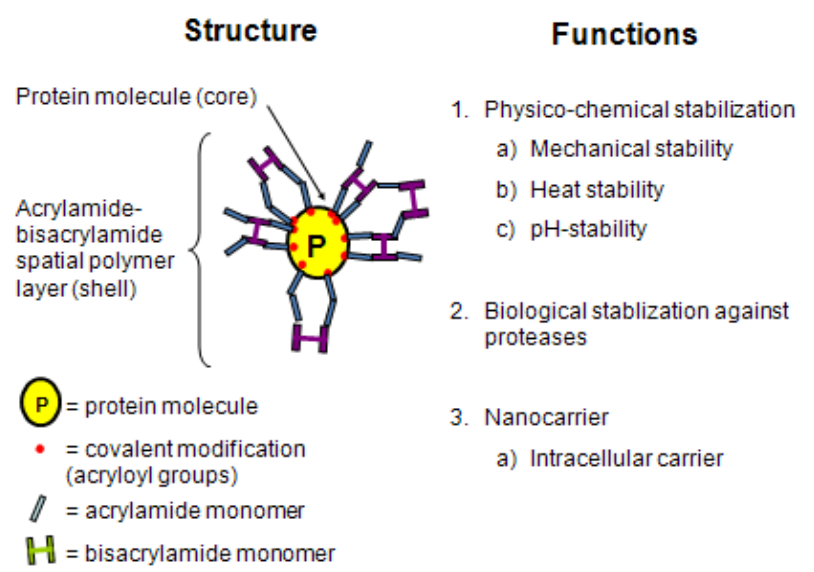

Fig. 2 Stability types of single protein nanoparticles.

The biocompatibility of haemoglobin nanocapsules covered by acrylamide-bisacrylamide random copolymer was investigated and good values were detected [36]. These results suggest immune isolation function of the polymer nanolayer but further investigations are needed.

Polymers are often used as protein drug carriers [37]. According to the literature, methacryloxypropyltrimethoxysilane [38] and acryl polymers [39] can go through biological membranes, have no toxicity and are biocompatible [40, 41]. These drug carriers have usually a greater size (in micrometer scale). Conventional polymeric drug carriers can not stabilize proteins, because protein drugs can be attached to the inner cavities of polymeric carriers by weak interactions only [37].

The investigation of the drug carrier function of SPNs (single protein nanoparticles) was started with studying the transport through the biological membranes. At first, the pass of SPNs through the blood-brain barrier was investigated. The blood-brain barrier is a metabolic barrier isolating the central nervous system from the systemic circulation [42-44]. The endothelial cells of blood-brain barrier are connected with very extensive tight junctions and hinder in the diffusion of hydrophilic molecules from the blood to the brain [42, 43]. Blood brain barrier normally does not allow the transport of proteins or peptide drugs [44]. For this reason, the facilitated transport of peptide and protein drugs through the blood brain barrier means great challenges in pharmaceutical sciences $[45,46]$.

\section{Materials and Methods}

\subsection{Materials}

Chemicals: Acryloyl chloryde (Sigma), disodium hydrogen phosphate, Potassinium dihydrogen phosphate (Spektrum-3d, Scharlau), acrylamide, bisacrylamide (Sigma), 3,5-dinitrosalicylic acid (Sigma), sodium metabisulphite (Spektrum-3D), phenol (Sigma), ammonium peroxodisulphate (Sigma), fluorescein isothiocyanate (Fluka), bovine serum albumin (Sigma), $\quad$ TEMED (N,N,N',N'-Tetramethylethylenediamine,

Sigma-Aldrich).

Instruments: Biochrom 4060 spectrophotometer (Pharmacia) was used for the detection of the protein concentration. Pictures were taken by a DP50 digital camera mounted on an Olympus BX-51 microscope (both from Olympus Optical Co. Ltd, Tokyo, Japan).

\subsection{Methods}

Preparation of SPNs (Fig. 3): A typical reaction contains the following steps: $250 \mathrm{mg}$ of bovine serum albumin was solved in $25 \mathrm{ml}$ of phosphate buffer (120 $\mathrm{mM}, \mathrm{pH}=7.15$, with a three times ion exchanged water, specific conductivity: $\rho=8.15 \mu \mathrm{S}$ ) and $3 \mathrm{mg}$ fluorescein isothiocyanate was added to the solution with a continuous stirring for 2 hours at room temperature. For the separation of the non-reacted FITC, dialysis was used (with a $12 \mathrm{~mm}$ diameter, 10 $\mathrm{kDa}$ cutoff dialysis tube, for $2 \times 6$ hours at $2{ }^{\circ} \mathrm{C}$ with a $120 \mathrm{mM}, \mathrm{pH}=7.15$ phosphate buffer to 10,000 times solution).

Modification of BSA on the surface: the solution was cooled to $0{ }^{\circ} \mathrm{C}$ and $100 \mu \mathrm{L}$ acryloyl chloride was added and stirred over a half an hour. $152 \mu \mathrm{L}$ of acrylamide/bisacrylamide (10:1 molar ratio of acrylamide: bisacrylamide) and $48.5 \mathrm{mg}$ ammonium 
peroxodisulphate and $2 \mu \mathrm{L}$ TEMED initiator was added into the solution under $\mathrm{N}_{2}$-atmosphere to initiate the polymerization reaction over 6 hours.

For the separation of the reagents and byproducts, dialysis was used again (with a $12 \mathrm{~mm}$ diameter, 10 $\mathrm{kDa}$ cutoff dialysis tube, for $2 \times 6$ hours at $2{ }^{\circ} \mathrm{C}$ with a $120 \mathrm{mM}, \mathrm{pH}=7.15$ phosphate buffer to 10,000 times solution).

Animal experiments: testing the permeability through the blood-brain barrier, the aforementioned material $(5 \mathrm{mg} / \mathrm{mL}$ albumin nanoparticles or $5 \mathrm{mg} / \mathrm{mL}$ control) was injected ( $1 \mathrm{~mL} / 100 \mathrm{~g}$ body weight, within $1 \mathrm{~min}$ ) into the inferior vena cava of adult Wistar albino rats (200-250 g) of either sex. The vena was exposed by median laparotomy. Animals received a deep ketamine-xylazine narcosis (20 and $80 \mathrm{mg} / \mathrm{kg}$ body weight, respectively, intramuscularly) before operation. The animals were decapitated after 1 to $10 \mathrm{~min}$, and the brains were fixed by immersion in $4 \%$ paraformaldehyde dissolved in $0.1 \mathrm{M}$ sodium phosophate buffer $(\mathrm{pH}=7.4)$ for 48 hours. Then coronal sections $(50 \mu \mathrm{m})$ were cut from the forebrains with a vibration microtome (vibratome). For negative controls, the same FITC-conjugated albumin was used but without coating by polymer layer. For positive controls, circumventricular organs (median eminence, subfornical organs, and area postrema) with 'leaky' blood-brain barrier [47-49] were studied. In some cases, the test-material was added together with $1 \%$ rhodamine solution.

\section{Results and Discussion}

For detection of the transport of SPNs through the blood brain barrier, fluorescent microscopy was used. FITC (Fluorescein isothiocyanate) was conjugated to bovine serum albumin (FITC-BSA) for the fluorescent images. This FITC-BSA conjugates was formed to single protein nanoparticles (FITC-SPN-BSA) as described above, and it was applied as test-material. For negative controls, the FITC-BSA was injected but without polymer layer. For positive controls, circumventricular organs (median eminence, subfornical organs, and area postrema) with 'leaky' blood-brain barrier were studied [47-49]. The FITC-BSA delineates the cerebral vessels and shows contrast around them. The lumen of the vessels is bright (see the bright formations are pointed by white arrows on Fig. 4a) but their local environment (the brain tissue in the other side of the brain blood barrier) is dark. It means that the FITC-BSA conjugates could not be transported through the blood brain barrier (Fig. 4a).

Contrary to it, the FITC-SPN-BSA conjugates formed a fluorescent 'cloud' on the picture of the histological slide in the aforementioned circumventricular organs (Fig. 4b, area postrema). This phenomenon is a sign of exudation of FITC-SPN conjugates through from the brain vessels to the brain tissue. This experiment showed that the control material (FITC-SPN) can also diffuse to the brain in

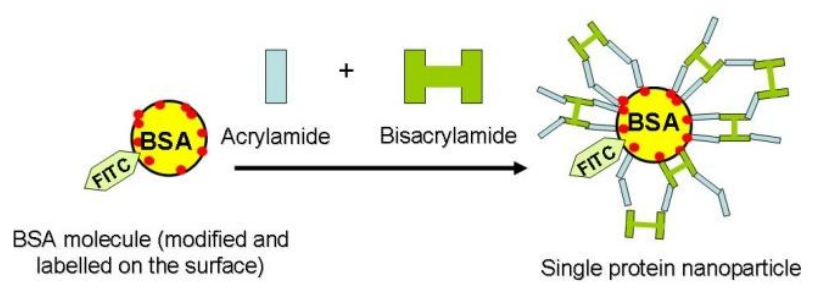

Fig. 3 Synthesis of single protein nanoparticles. Before the synthesis of nano-layer BSA was labeled with FITC andthen its surface was chemically modified (red points).

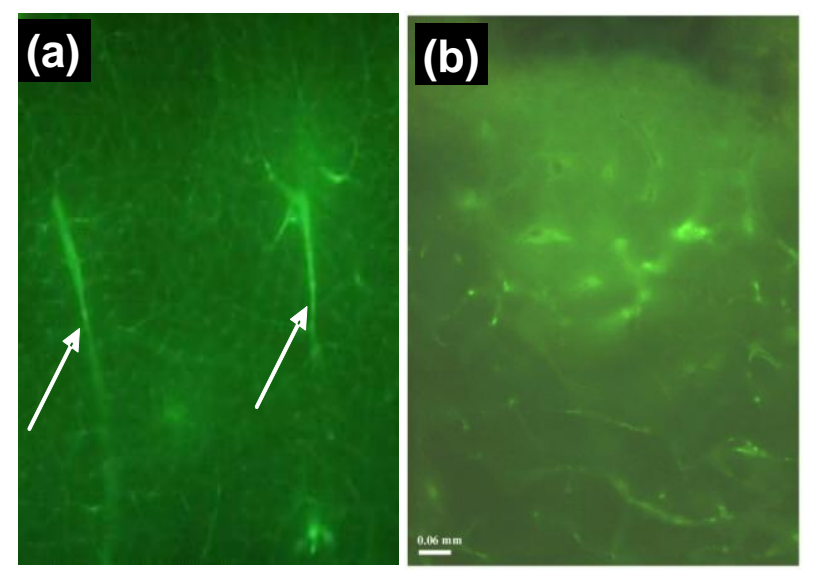

Fig. 4 (a) FITC-BSA without nano-layer was found inside the brain vessels only (arrows) (b) FITC-BSA without nano-layer covered in fluorescent "clouds" the areas of circumventricular organs (here the area postrema). 
that case when the blood brain barrier is not complete.

There were different time periods between the injection of drug conjugates to the rats and the decapitation of rats (from 1 to 10 minutes). Different stages of the drug transport from the vein of the rats to the brain tissue could be detected when time periods between the injection and the decapitation were differed (Figs. 5 and 6).

When the time period between the drug injection and the decapitation of the rats was $1 \mathrm{~min}$, the picture was still similar to that of FITC-BSA (Fig. 4a). The brain vessels contained FITC-SPN-BSA conjugates but the transport process from the lumen of the vessels to the brain tissue had not been finished yet. For this reason the lumen of the vessels is bright and contrast could be

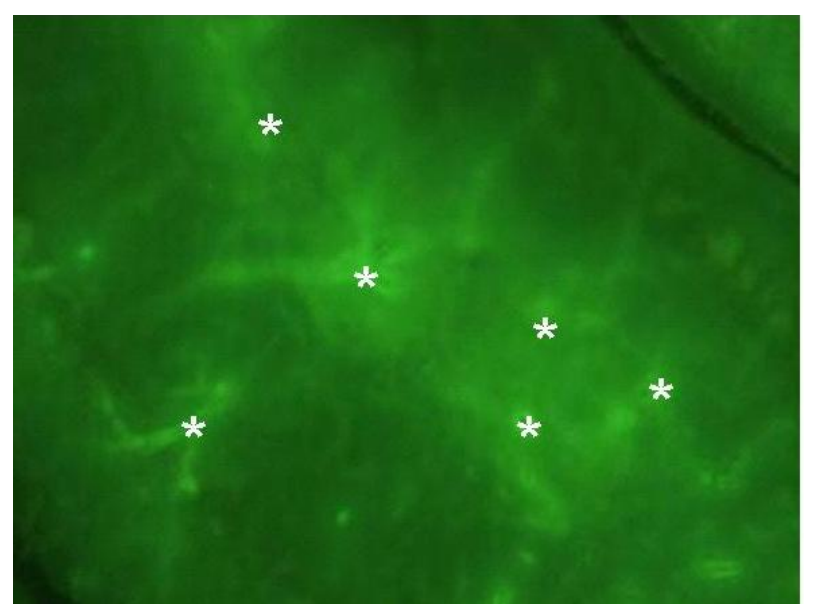

Fig. 5 FITC-SPN-BSA forms clouds over the brain vessels (stars) when applied in 2-3 minutes before decapitation.

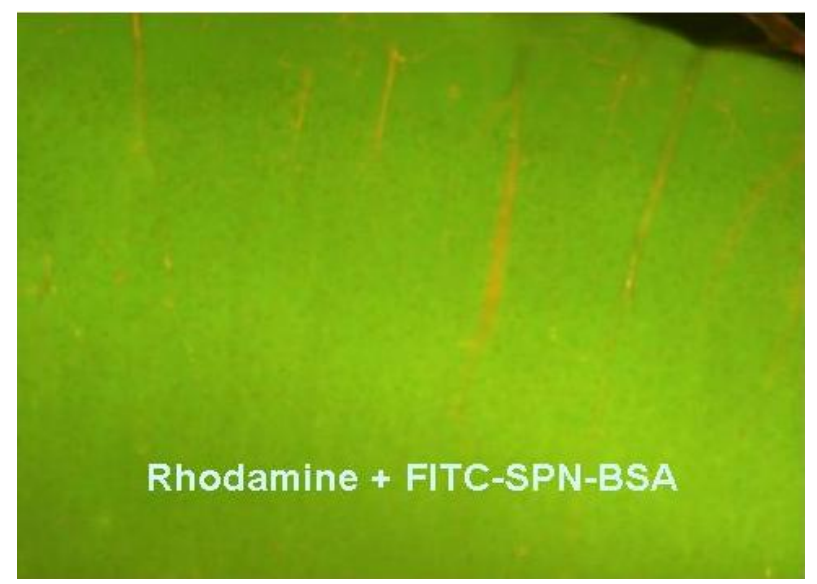

Fig. 6 FITC-SPN-BSA molecules can get through the BBB and colors green the brain tissue while rhodamine (red) remains on the vessels. detected between the lumens of vessels and the brain tissue which remained dark.

When the decapitation of the rats followed the injection of (FITC-SPN-BSA) solutions within 2-3 minutes, around the vessels fluorescent "clouds" indicated that the exudation is just going on (Fig. 5; brain vessels are signed by white stars on the picture). No sharp contours of the vessels could be detected. Similar phenomena were found in similar post-injection time intervals by Nitta et al. [50].

In some cases (e.g., hypoxic stage of brain or inflammation) the tight junctions of the brain blood barrier are disrupted and the paracellular permeability is increased [51]. It means that free (not encapsulated) albumin molecules can also diffuse from the blood to the cerebral tissue. Rhodamine was used to check whether an occasional leakiness underlies the penetration of the test material through the blood-brain barrier. In the blood the rhodamine molecules are bound to albumin, and its free fraction is transported out of the cells by the P-glycoprotein [52]. When rhodamine was injected together with the FITC-SPN-BSA, the former one remained inside the vessels delineating them (see red lines or stripes on Fig. 6), whereas the FITC-SPN-BSA stained the cerebral tissue around (see homogenous green areas on Fig. 6).

\section{Conclusion}

Single protein nanoparticles were synthesized from bovine serum albumin. Acrylamide-bisacrylamide random copolymer layer was synthesized around the surface of each individual protein molecules. This polymerization was initiated from the previously modified (acrylated) sites of the surface of albumin molecules. The polymer layer is thin (about 3-5 nm thick) but highly porous and allow to maintain the enzymatic function of encapsulated protein molecules. The main function of this layer is to stabilize the structure of encapsulated protein molecule.

For the animal experiments the single albumin nanoparticles were painted by FITC. This 
FITC-SPN-BSA conjugate was injected into the inferior vena cava of adult rats. Rats were decapitated after 1 to 10 minutes and histological sections of its brain were studied by fluorescent microscopy. The FITC-SPN-BSA conjugate was detected around the vessels of the rat brain within 2-3 minutes from the drug injection.

Rhodamine and FITC-SPN-BSA conjugate were also injected together and rats were decapitated after 10 minutes. In this case rhodamine remained inside the vessels delineating them, whereas the (FITC-SPN-BSA) conjugate stained the cerebral tissue around.

Results suggest that bovine serum albumin molecules as drugs encapsulated in polymer nano-layer with a small size (about $10 \mathrm{~nm}$ ) can pass through the blood brain barrier.

\section{Acknowledgement}

Experiments were supported by the Department of Anatomy, Histology and Embryology (Semmelweis University, Budapest) and the Research Institute of Chemical and Process Engineering (University of Pannonia). The technical assistance of Ms Szilvia Deák in the experimental operations is highly appreciated.

\section{References}

[1] Bummer, P. M. 2007. "Chemical Considerations in Protein and Peptide Stability." In Protein Formulation and Delivery, edited by McNally, E. J., McNally, E., and Hastedt, J. E. New York: CRC Press.

[2] Hooper, N. M. 2002. Proteases in Biology and Medicine. London: Portland Press.

[3] Cheetham, P. S. J. 1995. "Principles of Industrial Biocatalysis and Bioprocessing." In Handbook of Enzyme Biotechnology, edited by Wiseman, A. UK: Ellis Horwood, 83-234.

[4] Tischer, W., and Kasche, V. 1999. "Immobilized Enzymes: Crystals or Carriers?" Trends in Biotechnology 17 (8): 326-55.

[5] Livage, J., Coradin, T., and Roux, C. 2001. "Encapsulation of Biomolecules in Silica Gels."Journal of Physics-Condensed Matter13 (33): R673.

[6] Mozhaev, V. V., Melik-Nubarov, N. S., Sergeeva, M. V., Siksnis, V., and Martinek, K. 1990. "Strategy for
Stabilizing Enzymes. Part One: Increasing Stability of Enzymes via Their Multi-point Interaction with a Support." Biocatalysis 3 (3): 179-87.

[7] Mozhaev, V. V. 1993. "Mechanism-Based Strategies for Protein Thermostabilization." Trends in Biotechnology 11 (3): 88-95.

[8] Desantis, G., and Jones, J. B. 1999. "Chemical Modification of Enzymes for Enhanced Functionality." Current Opinion in Biotechnology 10 (4): 324-30.

[9] Govardhan, C. P. 1999. "Crosslinking of Enzymes for Improved Stability and Performance." Current Opinion in Biotechnology 10 (4): 331-5.

[10] Arnold, F. H., Wintrode, P. L., Miyazaki, K., and Gershenson, A. 2001. "How Enzymes Adapt: Lessons from Directed Evolution." Trends in Biochemical Sciences 26 (2): 100-6.

[11] Lehmann, M., and Wyss, M. 2001. "Engineering Proteins for Thermostability: The Use of Sequence Alignments versus Rational Design and Directed Evolution."Current Opinion in Biotechnology 12 (4): 371-5.

[12] Brannigan, J. A., and Wilkinson, A. J. 2002. "Protein Engineering 20 Years on." Nature Reviews Molecular Cell Biology 3 (12): 964-70.

[13] O'fagain, C. 2003. "Enzyme Stabilization-Recent Experimental Progress." Enzyme and Microbial Technology33 (2-3): 137-49.

[14] Klibanov, A. M. 2001. "Improving Enzymes by Using Them in Organic Solvents." Nature 409: 241-6.

[15] Lee M. Y., and Dordick, J. S. 2002. "Enzyme Activation for Non-aqueous Media." Current Opinion in Biotechnology 13 (4): 376-84.

[16] Caruana, C. M. 1997. "Enzymes Tackle Tough Processing." Chemical Engineering Progress 93 (11): 13-20.

[17] Demirjian, D., Moris-Varas, F., Gololobov, M., and Calugaru, S. 1999. "Biocatalysis in Chemical Processing." Chemical Process62 (6): 57-8.

[18] Antunes, A., Fierro, I., Guerrante, R., Mendes, F., and Alencar, M. S. 2013. "Trends in Nanopharmaceutical Patents." International Journal of Molecular Sciences 14 (4): 7016-31.

[19] Ge, J., Yang, C., Zhu, J., Lu, D., and Liu, Z. 2012. "Nanobiocatalysis in Organic Media: Opportunitiesfor Enzymes in Nanostructures." Topics in Catalysis 55 (16-18): 1070-80.

[20] Hong, R., Emrick, T., and Rotello, V. M. 2004. "Monolayer-Controlled Substrate Selectivity Using Noncovalent Enzyme-Nanoparticle Conjugates." Journal of American Chemical Society 126 (42): 13572-3.

[21] Yang, Z., Shihui, S., and Chunjing, Z. 2008. "Magnetic Single-Enzyme Nanoparticles with High Activity and Stability." Biochemical and Biophysical Research 
Communications 367 (1): 169-75.

[22] Hong, J., Xu, D., Gong, P., Ma, H., Dong, L., and Yao, S. 2007. "Conjugation of Enzyme on Superparamagnetic Nanogels Covered with Carboxil Groups." Journal of Chromatography B 850 (1-2): 499-506.

[23] Kumar, R., Maitra, A. N., Patanjali, P. K., and Sharma, P. 2005. "Hollow Gold Nanoparticles Encapsulating Horseradish Peroxidase.” Biomaterials 26 (33): 6743-53.

[24] Gill, I., and Ballesteros, A. 2000. "Bioencapsulation within Synthetic Polymers (Part 1): Sol-Gel Encapsulated Biologicals." Tibtech 18 (7): 282-96.

[25] Ge, Y., Min, Y., Lu, D., Zhang, M., and Liu, Z. 2007. "Hyperbranched Polymer Conjugated Lipase with Enhanced Activity and Stability." Biochemical Engineering Journal 36 (2): 93-9.

[26] Ma, D., Li, M., Patil, A. J., and Mann, S. 2004. "Fabrication of Protein/Silica Core-Shell Nanoparticles by Microemulsion-Based Molecular Wrapping." Advanced Materials 16 (20): 1838-41.

[27] Yang, Z., Shihui, S., and Chunjing, Z. 2008. "Magnetic Single-Enzyme Nanoparticles with High Activity and Stability." Biochemical and Biophysical Research Communications 367 (1): 169-75.

[28] Kim, J., Grate, J. W., and Wang, P. 2006. "Nanostructures for Enzyme Stabilization." Chemical Engineering Science 61 (3): 1017-26.

[29] Hegedüs, I., and Nagy, E. 2009. "Improvement of Enzyme Stability as Single Enzyme Nanoparticle." Chemical Engineering Science 64 (5): 1053-60.

[30] Hegedüs, I., and Nagy, E. 2009. "Comparision of the Structure and the Stability of Single Enzyme Nanoparticles." Hungarian Journal of Industrial Chemistry 37 (2): 123-30.

[31] Hegedüs, I., Nagy, E., Kukolya, J., Barna, T., and Fekete, Cs. A. 2011. "Cellulase and Hemicellulase Enymes as Single Molecular Nanobiocomposites." Hungarian Journal of Industrial Chemistry 39 (3): 341-8.

[32] Hegedüs, I., Hancsók, J., and Nagy, E. 2012. "Stabilization of the Cellulase Enzyme Complex as Enzyme Nanoparticle." Applied Biochemistry and Biotechnology 168 (6): 1372-83.

[33] Yan, M., Ge, Y., Liu, Z., and Ouyang, P. K. 2006. "Encapsulation of Single Enzyme in Nanogel with Enhanced Biocatalytic Activity and Stability." Journal of American Chemical Society 128 (34):11008-9.

[34] Yan, M., Du, J., Gu, Z., Liang, M., Hu, Y., Zhang, W., Priceman, S., Wu, L., Zhou, Z. H., Liu, Z., Segura, T., Tang, Y., and Lu, Y. 2010. "A Novel Intracellular Protein Delivery Platform Based on Single-Protein Nanocapsules." Nature Nanotechnology 5: 48-53.

[35] Wen, J., Anderson, S. M., Du, J., Yan, M., Wang, J., Shen, M., Lu, Y., and Segura, T. 2011. "Controlled Protein
Delivery Based on Enzyme-Responsive Nanocapsules." Advanced Materials 23 (39): 4549-53.

[36] Hegedüs, I., Kiss-TóthDojcsak, É., JuhásznéSzalai, A., Lovrity, Z., Emmer, J., Koska, P., Fodor, B., and Nagy, E. 2014. "Single Haemoglobin Nanocapsules as Test Materials for Artificial Blood." Periodica Polytechnica Chemical Engineering 58 (Sup): 11-6.

[37] Lee, K. Y., and Yuk, S. H. 2007. "Polymeric Protein Delivery Systems." Progress in Polymer Science 32 (7): 669-97.

[38] Mori, A., Ohtsuki, C., Sugino, A., Kuramoto, K., Miyazaki, T., Tanihara, M., and Osaka, A. 2003. "Bioactive MMPA-Based Bone Cement Modified with Methacryloxypropylthrimethoxysilane and Calcium Salts." Journal of the Cheramic Society of Japan 111 (10): 738-42.

[39] Al-Karawi, A. J. M., and Al-Daraji, A. H. R. 2010. "Preparation and Using of Acrylamide Grafted Starch as Polymer Drug Carrier." Carbohydrate Polymers 79 (3): 769-74.

[40] Shirosaki, Y., Tsuru, K., Hayakawa, S., Osaka, A., and Takashima, S. 2006. "Cytocompatibility of Silicon Elastomer Grafted with $\beta$-Methacryloxypropylthrimethoxysilane." Journal of the Cheramic Society of Japan 114 (1): 72-6.

[41] Vallée, J.-N., Lo, D., Guillevin, R., Reb, P., Adem, C., and Chiras, J. 2003. "In Vitro Study of the Compatibility of Tris-acryl Gelatin Microspheres with Various Chemotherapeutic Agents." Journal of Vascular and Interventional Radiology14 (5): 621-8.

[42] Ballabh, P., Braun, A., and Nedergaard, M. 2004. "The Blood-Brain Barrier: An Overview: Structure, Regulation, and Clinical Implications." Neurobiology of Disease 16 (1): 1-13.

[43] Cardoso, F. L., Brites, D., and Brito, M. A. 2010. "Looking at the Blood-Brain Barrier: Molecular Anatomy and Possible Investigation Approaches." Brain Research Reviews 64 (2): 328-63.

[44] Correale, J., and Villa, A. 2009. "Cellular Elements of the Blood-Brain Barrier." Neurochemical Research 34: 2067-77.

[45] Brasnjevic, I., Steinbusch, H. W. M., Schmitz, C., and Martinez-Martinez, P. 2009. "Delivery of Peptide and Protein Drugs over the Blood-Brain Barrier." Progress in Neurobiology 87 (4): 212-51.

[46] Pardridge, W. M. 1999. "Blood-Brain Barrier Biology and Methodology.” Journal of Neurovirology 5 (6): 556-69.

[47] Krisch, B., Leonhardt, H., and Buchheim, W. 1978. "The Functional and Structural Border of the Neurohemal Region of the Median Eminence." Cell Tissue Research 192 (2): 327-39.

[48] Krisch, B., Leonhardt, H., and Buchheim, W. 1978. "The Functional and Structural Border Between the CSF-and 
Blood-Milieu in the Circumventricular Organs (Organum Vasculosum Laminae Terminalis, Subfornical Organ, Area Postrema) of the Rats." Cell Tissue Research 195 (3): 485-97.

[49] Palkovits, M. 1986. "Summary of Structural and Functional Aspects of the Circumventricular Organs" In: Circumventricular Organs and Body Fluids, Vol. II., edited by Gross, P. M. Boca Raton, Florida: CRC Press Inc., 209.

[50] Nitta, T., Hata, M., Gotoh, S., Seo, Y., Sasaki, H., Hashimoto, N., Furuse, M., and Tsukita, S. 2003.
"Size-Selective Loosening of the Blood-Brain Barrier in Claudin-5-Deficient Mice." Journal of Cell Biology 161 (3): 653-60.

[51] Huber, J. D., Egleton, R. D., and Davis, T. P. 2001. "Molecular Physiology and Pathophysiology of Tight Junctions in the Blood-Brain Barrier." Trends in Neurosciences 24 (12): 719-25.

[52] Kusuhara, H., and Sugiyama, Y. 2001. "Efflux Transport Systems for Drugs at the Blood-Brain Barrier and Blood-Cerebrospinal Fluid Barrier (Part 1)." Drug Discovery Today 6 (3): 150-6. 